\title{
The Psychological Inflexibility in Pain Scale (PIPS): Validity and Reliability of the Japanese Version for Chronic Low Back Pain and Knee Pain
}

This article was published in the following Dove Press journal: Journal of Pain Research

\author{
Yasuhiro Nagasawa (iD) 1,2 \\ Ai Shibata (D) ${ }^{3}$ \\ Hanako Fukamachi ${ }^{4,5}$ \\ Kaori Ishii iD ${ }^{5}$ \\ Rikard K Wicksell ${ }^{6}$ \\ Koichiro Oka iD ${ }^{5}$ \\ 'Department of Rehabilitation, Hasegawa \\ Hospital, Yachimata, Chiba, Japan; \\ ${ }^{2}$ Graduate School of Sport Sciences, \\ Waseda University, Tokorozawa, Saitama, \\ Japan; ${ }^{3}$ Faculty of Health and Sports \\ Sciences, University of Tsukuba, Tsukuba, \\ Ibaraki, Japan; ${ }^{4}$ Sport Sciences \\ Laboratory, Japan Sport Association, \\ Tokyo, Japan; ${ }^{5}$ Faculty of Sport Sciences, \\ Waseda University, Saitama, Japan; \\ ${ }^{6}$ Department of Clinical Neuroscience, \\ Karolinska Institute, Stockholm, Sweden
}

\begin{abstract}
Purpose: The aim of this study was to translate the Psychological Inflexibility in Pain Scale Japanese version (PIPS-J) and inspect its validity and reliability in older patients with chronic low back pain and knee pain.
\end{abstract}

Materials and Methods: The PIPS was translated into Japanese by a bilingual linguistic expert and three researchers and administered to 120 outpatients with low back pain and knee pain $(61.7 \%$ women, age $73.8 \pm 7.8$ years). Construct validity and criterion validity were evaluated using confirmatory factor analysis and the correlations with the Acceptance and Action Questionnaire-II Japanese version (AAQ-II-J) and the Cognitive Fusion Questionnaire Japanese version (CFQ-J), respectively. Internal consistency using Cronbach's alpha and test-retest reliability $(\mathrm{n}=43)$ were also examined.

Results: Of all, $78.3 \%$ had low back pain, $55.6 \%$ had knee pain, and $44.2 \%$ both. The confirmatory factor analysis reproduced the original PIPS structure with two factors and indicated good model fit $(\mathrm{GFI}=0.915, \mathrm{CFI}=0.970$, RMSEA $=0.060)$. All items' standardized regression weights ranged from 0.35 to 0.80 . Criterion validity was shown by correlations of $\mathrm{r}=0.58$ for PIPS-J pain avoidance with the AAQ-II-J, and $\mathrm{r}=0.45$ between PIPS-J cognitive fusion and the CFQ-J. Cronbach's alpha for the PIPS-J total score was $\alpha=0.85$ (pain avoidance: 0.87; cognitive fusion: 0.68). The test-retest correlation for all 12 items was $\mathrm{r}=0.54$ (pain avoidance: 0.48 ; cognitive fusion: 0.54 ).

Conclusion: Although a less relevant item was found on each of subscales, the PIPS-J appear to be fairly valid and reliable to evaluate psychological inflexibility in chronic pain among Japanese older adults.

Keywords: pain avoidance, cognitive fusion, older patients, chronic low back pain, chronic knee pain

\section{Introduction}

Chronic pain is a common health problem constituting a significant burden on not only the physical, mental, and social functioning of individuals but also the economy and society. For example, chronic low back pain and knee pain are a major health issue among the growing population of older adults in Japan. Japanese epidemiological studies have revealed that the prevalence of low back pain, knee pain, and their combination was $37.7 \%, 32.7 \%$, and $12.2 \%$, respectively. ${ }^{1}$ These pains were reported to cause a significant decline in walking ability, disability, and quality of life. ${ }^{2}$ Cognitive Behavioral Therapy (CBT), a wellknown psychological treatment for chronic pain, has been utilized to improve
Correspondence: Yasuhiro Nagasawa Department of Rehabilitation, Hasegawa Hospital, 85 Yachimatani, Yachimata, Chiba, 289-I 103, Japan

Tel +8I 34440137

$\mathrm{Fax}+8134440807$

Email nagasawaid@toki.waseda.jp 
coping strategies for pain. Although CBT, which focuses on reducing pain and related distress as well as improving functioning and quality of life, by eg changing pain-related maladaptive thoughts, has strong empirical support. However, previous study has shown that CBT has relatively small beneficial effects on reducing pain, disability, and distress in patients with chronic pain. ${ }^{3}$ Thus, there need to improve psychological approaches to treat pain and disability remains.

During the last decade, there has been growing interest in Acceptance and Commitment Therapy (ACT), developed within CBT. Rather than trying to control or reducing pain itself, as in traditional CBT, ${ }^{4}$ ACT emphasizes acceptance of pain and distress in the service of increasing valued action in the presence of pain and other negative psychological experiences, ie psychological flexibility. ${ }^{5}$ A recent randomized controlled trial comparing ACT and CBT for older adults with chronic pain found that ACT was more effective for pain reduction than $\mathrm{CBT}^{6}$

High-quality measures are essential to evaluate intervention effects. The assessment of ACT for chronic pain includes the Chronic Pain Acceptance Questionnaire $(\mathrm{CPAQ})^{7}$ and the Psychological Inflexibility in Pain Scale (PIPS). ${ }^{8,9}$ The CPAQ aims to measure acceptance (willingness, activity engagement) of chronic pain, whereas PIPS evaluates components of psychological inflexibility (avoidance and fusion), as part of the psychopathology model of ACT that includes "experiential avoidance," "cognitive fusion," "lack of values clarity," "unworkable action," "dominance of the conceptualized past and feared future," and "attachment to the conceptualized self". ${ }^{10}$ Among these, experiential avoidance and cognitive fusion are considered important psychological processes strongly influencing behaviors. Thus, the 12-item PIPS comprises two subscales, pain avoidance ( 8 items) and cognitive fusion (4 items). Previous study confirmed an acceptable validity and reliability. ${ }^{9}$ Also, the instrument has been shown to capture indirect effects, which is important for its use as a process measure. ${ }^{8}$ Furthermore, PIPS is sensitive to change in both digital and standard exposure based interventions, ${ }^{11,12}$ and found to be a mediator of treatment outcome. $^{13,14}$ Thus, previous research supports the utility of PIPS for evaluating treatment effects in ACT and other forms of exposure-based interventions.

Recently, PIPS has been translated to Spanish, ${ }^{15}$ Dutch, $^{16}$ German, ${ }^{17}$ Iran, ${ }^{18,19}$ Greek, $^{20}$ and Chinese ${ }^{21}$ shown to have acceptable validity and reliability. However, there is yet no Japanese version of the PIPS.
An increased interest in ACT in Japan, due to eg the large number of older adults with chronic pain, indicates the importance of validating PIPS in Japanese since it would be difficult to develop and implement ACT and similar interventions without an adequate measure of the effects. Thus, development of a Japanese version of the PIPS (PIPS-J) is essential, and the aim of the present study was therefore to translate and the PIPS into Japanese, and to examine the validity and reliability of the PIPS-J in older patients with chronic low back pain and chronic knee pain.

\section{Materials and Methods \\ Participants}

Participants were recruited from an outpatient orthopedics and rehabilitation at Hasegawa Hospital, Chiba, Japan, between January and March 2019. This hospital has a medical system which provides detailed support for various diseases and disorders specialized for elderly patients. In addition to posting advertisements with information about the study in the waiting rooms, physical therapists informed eligible patients about the opportunity to participate in the study after confirming whether they were going to the hospital because of low back pain and/or knee pain symptom. Inclusion criteria were adults aged 65 or older, presence of persistent low back pain and/or knee pain for three months or longer, and independent mobility. The exclusion criterion was an inability to respond to the questionnaire due to cognitive impairment.

After agreeing to participate in this study, the questionnaire was directly distributed to patients at the hospital, who were asked to answer the questionnaire at home and submit it to a physical therapist at their next visit. Also, the diagnosis status was confirmed with the doctor with the permission of the participants. Written informed consent was obtained from all participants. In total, 145 older adults participated in this study. Of these, 10 were 64 years old or younger and 6 had no pain and 9 had pain persistence within 3 months. The final study sample was 120. For test-retest reliability, 43 of the 120 participants were randomly selected as a subsample, and the second assessment was conducted at an interval of 2 weeks from the first assessment. The ethics of this study were approved by the affiliation of author. The study was approved by the Human Research Ethics Committee of Waseda University (No. 2018-080) and conformed to the principles outlined in the Declaration of Helsinki. 


\section{Measures}

\section{Psychological Inflexibility}

The PIPS-J was developed to measure psychological inflexibility in relation to chronic pain. In the original version of the instrument, comprising 12 items, 8 items assessed pain-related avoidance behaviors, while 4 items measured levels of cognitive fusion in relation to pain. 8 All the items were rated on a 7-point Likert-type scale from 1 (never true) to 7 (always true). The total score was calculated by summing the responses for each of the 12 items, where higher scores indicate greater psychological inflexibility.

\section{Experiential Avoidance}

The Acceptance Action Questionnaire-II (AAQ-II), a 7-item self-reported questionnaire, was utilized to measure experiential avoidance. ${ }^{22}$ Each item was rated on a scale from 1 (never true) to 7 (always true), where a higher score indicates engagement in more avoidance behaviors. The AAQ-II Japanese version (AAQ-II-J) demonstrates good validity. ${ }^{23}$

\section{Cognitive Fusion Questionnaire}

The Cognitive Fusion Questionnaire (CFQ), a 7-item selfreported questionnaire, was used to measure cognitive fusion. ${ }^{24}$ Each item was rated on a scale from 1 (never true) to 7 (always true), where a higher score indicates greater application of cognitive fusion. The CFQ Japanese version (CFQ-J) has been reported to show good psychometric properties. ${ }^{25}$

\section{Sociodemographic and Health-Related Variables}

Sociodemographic attributes and health-related variables included age, gender, height, weight, Body Mass Index (BMI), education level, material status, number of pain sites, duration pain, and diagnosis. A self-report questionnaire measured age, gender, height, weight, education level (high school or further education; lower secondary school or less), marital status (currently married; single), number of pain sites, and duration pain. BMI was calculated based on measured height and weight. The diagnosis was confirmed from the medical record.

\section{Translation and Validation Process}

The PIPS-J translation process was conducted with reference to the International Society for Pharmacoeconomics and Outcomes Research. ${ }^{26}$ Permission to translate and validate the PIPS was first obtained from one of the original authors. The PIPS was then translated from its
English version into Japanese by one translator bilingual in Japanese/English and three researchers. The meaning of the translation of each item translated into Japanese was discussed by four researchers (two health psychologists, one gerontologist, and one physical physiologist) and a Japanese version was agreed upon. The translated Japanese version was then back-translated into English by two Japanese/English bilinguals without specific knowledge of this instrument (outside translation vendor). The final back-translation version was then compared to the original English by the original author, discrepancies identified in the back translations, and clarification provided of the intent behind the items. The following process was repeated up to achieving final agreement: Modification of the Japanese based on comments of the original author, discussion of the meaning of modifications by four researchers, back-translation by two bilinguals, and comparison with the original version by the original author.

\section{Data Analysis}

Estimation of validity was conducted for construct validity and criterion validity. For construct validity, Confirmatory Factor Analysis (CFA) was applied to investigate whether the factor structure corresponded with the original version. CFA model fit was assessed with a $\chi^{2}$ test and $\chi^{2} / \mathrm{df}$ ratio, Goodness of Fit Index (GFI), Comparative Fit Index (CFI), Root Mean Square Error of Approximation (RMSEA), and Akaike Information Criterion (AIC). Values of GFI greater than 0.90 indicate an accepted fit to the data, while for the CFI, values above 0.95 suggest an acceptable fit and values above 0.97 a good fit. RMSEA values below 0.05 are considered to indicate a good-fitting model, values below 0.08 are indicative of an accepted fit. ${ }^{27}$ If the factor analysis model needed to be modified, AIC was used to compare the model before and after modification. This study is a reasonable sample size, as the CFA requires 5 to 10 times the observed variables for sample size of this study. ${ }^{28}$ For the criterion validity of the PIPS-J subscales, pain avoidance and cognitive fusion were investigated with their correlation coefficients with AAQ-II-J and CFQ-J, respectively. For estimates of reliability, internal consistency and test-retest reliability were examined using Cronbach's alpha and correlation coefficients. The data were analyzed using IBM SPSS Statistics 25.0 for Windows (IBM SPSS Japan, Inc., Tokyo, Japan), while for the CFA, Amos 25.0 for Windows (IBM SPSS Japan, Inc., Tokyo, Japan) was used. 
Table I Characteristics of the Participants

\begin{tabular}{|c|c|c|}
\hline & $\begin{array}{l}\text { Mean or } \\
\text { Number }\end{array}$ & $\begin{array}{l}\text { SD or } \\
\%\end{array}$ \\
\hline Age (year) & 73.8 & 7.8 \\
\hline Height (cm) & 155.8 & 9.8 \\
\hline Weight (kg) & 58.3 & 11.3 \\
\hline BMI & 23.9 & 3.6 \\
\hline \multicolumn{3}{|l|}{ Sex (number, \%) } \\
\hline Female & 74 & 61.7 \\
\hline Male & 46 & 38.3 \\
\hline \multicolumn{3}{|l|}{ Marital status (number, \%) } \\
\hline Married & 106 & 88.3 \\
\hline Single & 14 & 11.7 \\
\hline \multicolumn{3}{|l|}{ Education level (number, \%) } \\
\hline Junior high school & 27 & 22.5 \\
\hline High school & 75 & 62.5 \\
\hline Junior college & 7 & 5.8 \\
\hline University & 11 & 9.2 \\
\hline \multicolumn{3}{|l|}{ Pain site (number, \%) } \\
\hline Low back & 94 & 78.3 \\
\hline Knee & 78 & 65.0 \\
\hline Both low back and knee & 51 & 42.5 \\
\hline Pain duration (month) & 82.4 & 114.9 \\
\hline \multicolumn{3}{|l|}{ Diagnosis } \\
\hline $\begin{array}{l}\text { Lumber degenerative disc } \\
\text { disease }\end{array}$ & 50 & 41.6 \\
\hline Lumber spinal stenosis & 30 & 25.0 \\
\hline Spondylosis deformans & 15 & 12.5 \\
\hline Lumbar disk herniation & 7 & 5.8 \\
\hline Knee osteoarthritis & 76 & 63.3 \\
\hline Total knee arthroplasty & 4 & 3.3 \\
\hline
\end{tabular}

Abbreviation: BMI, body mass index.

\section{Results}

\section{Characteristics of the Participants}

The characteristics of the participants are summarized in Table 1 . The mean age of the 120 participants was 73.8 (SD:7.8) years; $74(61.7 \%)$ were woman, while 39 $(32.5 \%)$ were overweight under the standard interpretation of BMI. In addition, 75 (62.5\%) participants were high school graduates and $106(88.3 \%)$ were married. For location of pain, $94(78.3 \%)$ had low back pain, 78 $(65.0 \%)$ had knee pain, and 51 (42.5\%) had both low back pain and knee pain. Furthermore, the mean duration of pain was 82.4 (SD:114.9) months. Lumber degenerative disc disease was the most common diagnosis of low back pain $50(41.6 \%)$, and knee osteoarthritis $76(63.3 \%)$ was most common diagnosis of knee pain.

\section{Validity of the PIPS-J Construct Validity}

The PIPS-J was shown to have two factors with eight pain avoidance and four cognitive fusion items by CFA (Table 2). The model fit indices were satisfactory upon setting error correlations between Items 1 and 8, Item 1 and 9, Items 2 and 3, Item 3 and 6, Item 3 and 11, Item 4 and 11, Items 5 and 7, and Item 9 and 10 (Before modification: $\chi^{2}=139.31, \mathrm{df}=53, \mathrm{P}=0.001$ with a ratio of $\chi^{2} / \mathrm{df}=2.62$, GFI $=0.831$, CFI $=0.867$, RMSEA $=0.117$, AIC $=189.3$; after modification: $\chi^{2}=$ $64.08, \mathrm{df}=45, \mathrm{P}=0.032$ with a ratio of $\chi^{2} / \mathrm{df}=1.42$, $\mathrm{GFI}=0.915$, CFI $=0.970$, RMSEA $=0.060, \mathrm{AIC}=$ 130.0). Both PIPS-J subscales were positively intercorrelated with a standardized regression weight of 0.47 . The standardized regression weight of all 12 items ranged from 0.35 to 0.80 . Item 2 (pain avoidance) and Item 3 (cognitive fusion) had low standardized regression weights.

\section{Criterion Validity}

Meaningful positive moderate correlations were found between the PIPS-J subscale of pain avoidance and the AAQ-II-J $(r=0.58, P<0.01)$. Furthermore, positive moderate correlations were obtained between PIPS-J subscale cognitive fusion and the CFQ-J $(\mathrm{r}=0.45, \mathrm{P}<0.01)$.

\section{Reliability of the PIPS-J Internal Consistency}

Cronbach's alpha for all 12 items of the PIPS-J was 0.85 , indicating a high degree of internal consistency, while that of the 8 items of the subscale of pain avoidance was 0.87 and that of the 4 items of the subscale of cognitive fusion was 0.68 , so both subscales indicated a satisfactory degree of internal consistency.

\section{Test-Retest Reliability}

Among the 43 members of the subsample, the subscale of pain avoidance had a positive moderate correlation $(\mathrm{r}=$ $0.48, \mathrm{P}<0.01)$, as did the subscale of cognitive fusion $(\mathrm{r}=$ $0.54, \mathrm{P}<0.01)$ and the total score $(\mathrm{r}=0.54, \mathrm{P}<0.01)$.

\section{Discussion}

The present study evaluated the validity and reliability of PIPS-J for older patients with chronic low back pain and knee pain. Although some items had smaller influence on the subscales of pain avoidance and cognitive fusion, the PIPS-J was found to be fairly valid and reliable, 
Table 2 Confirmatory Factor Analysis of the PIPS-J

\begin{tabular}{|c|c|c|c|c|c|c|c|c|}
\hline \multirow{3}{*}{\multicolumn{3}{|c|}{ Item }} & \multirow[t]{3}{*}{ Mean } & \multirow[t]{3}{*}{ SD } & \multicolumn{2}{|l|}{ Model I } & \multicolumn{2}{|l|}{ Model 2} \\
\hline & & & & & \multicolumn{2}{|c|}{$\begin{array}{l}\text { Standardized Regression } \\
\text { Weight }\end{array}$} & \multicolumn{2}{|c|}{$\begin{array}{l}\text { Standardized Regression } \\
\text { Weight }\end{array}$} \\
\hline & & & & & $\begin{array}{l}\text { Pain } \\
\text { Avoidance }\end{array}$ & $\begin{array}{l}\text { Cognitive } \\
\text { Fusion }\end{array}$ & $\begin{array}{l}\text { Pain } \\
\text { Avoidance }\end{array}$ & $\begin{array}{l}\text { Cognitive } \\
\text { Fusion }\end{array}$ \\
\hline I & \multirow{2}{*}{\multicolumn{2}{|c|}{$\begin{array}{l}\text { I cancel planned activities } \\
\text { when I am in pain. } \\
\text { I say things like "I don't have } \\
\text { any energy," "I am not well } \\
\text { enough," "I don't have time” } \\
\text { "I don't dare," “I have too } \\
\text { much pain," "I feel too bad," } \\
\text { or "I do not feel like it”. }\end{array}$}} & 2.78 & 1.52 & 0.59 & & 0.53 & \\
\hline 2 & & & 3.19 & 1.55 & 0.48 & & $0.4 I$ & \\
\hline 3 & \multicolumn{2}{|c|}{$\begin{array}{l}\text { I need to understand what is } \\
\text { wrong in order to move on. }\end{array}$} & 3.36 & 1.74 & & 0.39 & & 0.35 \\
\hline 4 & \multicolumn{2}{|c|}{$\begin{array}{l}\text { Because of my pain, I no } \\
\text { longer plan for the future. }\end{array}$} & 2.56 & 1.70 & 0.77 & & 0.71 & \\
\hline 5 & \multirow{2}{*}{\multicolumn{2}{|c|}{$\begin{array}{l}\text { I avoid doing things when } \\
\text { there is a risk it will hurt or } \\
\text { make things worse. } \\
\text { It is important to understand } \\
\text { what causes my pain. }\end{array}$}} & 3.42 & 1.72 & 0.70 & & 0.71 & \\
\hline 6 & & & 4.11 & 1.77 & & 0.64 & & 0.60 \\
\hline 7 & \multicolumn{2}{|c|}{$\begin{array}{l}\text { I do not do things that are } \\
\text { important to me to avoid pain. }\end{array}$} & 2.88 & 1.57 & 0.72 & & 0.72 & \\
\hline 8 & \multicolumn{2}{|c|}{$\begin{array}{l}\text { I postpone things because of } \\
\text { my pain. }\end{array}$} & 2.88 & 1.53 & 0.73 & & 0.73 & \\
\hline 9 & \multicolumn{2}{|c|}{$\begin{array}{l}\text { I would do almost anything to } \\
\text { get rid of my pain. }\end{array}$} & 4.16 & 1.60 & & 0.74 & & 0.79 \\
\hline 10 & \multicolumn{2}{|c|}{$\begin{array}{l}\text { It's not me that controls my } \\
\text { life, it's my pain. }\end{array}$} & 2.47 & 1.71 & 0.79 & & 0.79 & \\
\hline II & \multirow{2}{*}{\multicolumn{2}{|c|}{$\begin{array}{l}\text { I avoid planning activities } \\
\text { because of my pain. } \\
\text { It is important that I learn to } \\
\text { control my pain. }\end{array}$}} & 2.68 & 1.76 & 0.84 & & 0.80 & \\
\hline 12 & & & 4.08 & 1.68 & & 0.80 & & 0.80 \\
\hline \multirow{3}{*}{$\begin{array}{l}\text { Model fit } \\
\text { indices }\end{array}$} & & $X^{2}(\mathrm{df})$ & \multicolumn{2}{|l|}{$X^{2} / \mathrm{df}$} & GFI & CFI & RMSEA & AIC \\
\hline & Model I & $|39.3|(53)^{*}$ & \multirow{2}{*}{\multicolumn{2}{|c|}{$\begin{array}{l}2.62 \\
1.42\end{array}$}} & 0.831 & 0.867 & 0.117 & 189.3 \\
\hline & Model 2 & $64.08(45)$ & & & 0.915 & 0.970 & 0.060 & 130.0 \\
\hline
\end{tabular}

Note: *Significant differences at $\mathrm{p}<0.001$.

Abbreviations: GFI, Goodness of Fit Index; CFI, Comparative Fit Index; RMSE, root mean square error of approximation; AIC, Akaike Information Criterion.

suggesting that the PIPS-J is a theoretical construct common to various races and environments because it has same structure in different races, cultures, and environments. Also, the PIPS-J can accurately measure psychological inflexibility in older patients with chronic pain and be used to evaluation ACT and similar interventions.

In previous studies, the original PIPS was translated into Spanish, ${ }^{15}$ Dutch,,${ }^{16}$ German, ${ }^{17}$ Iran, ${ }^{18,19}$ Greek, ${ }^{20}$ and
China $^{21}$ and was used as a scale of ACT for chronic pain. In Japan, the AAQ-II-J has been used as an evaluation scale for ACT. However, it is a generic scale, and not specific to a pain context. Also, it evaluates only experiential avoidance (eg not cognitive fusion), which is shown to impact valued action. ${ }^{10}$ Originally, the development process of the PIPS was based on psychological inflexibility, including cognitive fusion. ${ }^{9}$ Thus, the results of the 
present study indicate that the effects of ACT on chronic pain can be accurately evaluated in not only foreign countries but also in Japan. Furthermore, previous studies examining the psychometric properties of the PIPS targeted a general adult population. ${ }^{15-18,20,21}$ The average age of participants in the previous studies was 43 to 57 years, which may indicate that they included a few participants over 65 years. Based on the results of this study of people over 65 years, PIPS can be used not only for middle-aged but also older populations.

The PIPS-J comprises two subscales with eight pain avoidance items and four cognitive fusion items via CFA. The model showed good overall fit, but Items 2 (I say things like 'I don't have any energy,' 'I am not well enough,' 'I don't have time,' 'I don't dare,' 'I have too much pain,' 'I feel too bad,' or 'I don't feel like it') and 3 ("I need to understand what is wrong in order to move on") had smaller effects on the pain avoidance and cognitive fusion subscales, respectively. Similar to the present study, the previous study developing the PIPS Greek ${ }^{20}$ version also showed lower influence for Item 2 and 3. Although the previous study developing PIPS Chinese version $^{21}$ revealed higher weight for item 2 and 3, some minor modifications were made after translation considering cultural and linguistic differences. Indeed, item 2; "I am not well enough," and "I don't dare", and item 3; "move on" were also difficult to translate into suitable Japanese expressions. Therefore, it took a considerable amount of time to achieve final agreement on the translation and back-translation process in the present study. These findings imply that simple translation from English especially for item 2 and 3 may not enough sufficient to read or interpret intent of questions accurately as other language expression like Japanese and Chinese. Minor modifications which take linguistic and cultural differences into consideration may need to improve contribution for item 2 and 3. As an additional implication for a small effect of item 3 on cognitive fusion, Barke et al ${ }^{17}$ indicated that Item 3 does not refer to the participant's own pain in contrast to the other items in the fusion subscale. In this study, some participants may also have answered Item 3 on the PIPS-J as a general statement rather than a statement referring to their own pain. On the other hand, the Chinese version of PIPS ${ }^{21}$ was modified item 3 with "I need to understand what's wrong with my pain sites in order to move on." and obtained higher effects on it. Therefore, it is probably advisable to modify the question to refer to the participant's own pain.
The present study had some limitations. First, since the participants of this study were recruited at only one facility, there is a likelihood of selection bias. Second, the PIPS-J as validated in this study may not be applicable to all Japanese chronic pain patients because it only targeted older patients with low back pain and knee pain. Therefore, the findings may not be generalizable to the broader population with chronic pain. The PIPS-J may further need be validated with individuals who have other chronic pain.

\section{Conclusion}

The PIPS-J has been shown to be a valid and reliable scale for measuring psychological inflexibility in older patients with chronic low back pain and knee pain. Future studies are needed to investigate the impact of psychological inflexibility on older patients with chronic pain, as well as the effects of ACT and similar exposure-based interventions.

\section{Abbreviations}

CBT, cognitive behavioral therapy; ACT, acceptance and commitment therapy; CPAQ, Chronic Pain Acceptance Questionnaire; PIPS, Psychological Inflexibility in Pain Scale; PIPS-J, Japanese version of the Psychological Inflexibility in Pain Scale; AAQ-II, Acceptance Action Questionnaire-II; AAQ-II-J, Acceptance Action Questionnaire-II Japanese version; CFQ, Cognitive Fusion Questionnaire; CFQ-j, Cognitive Fusion Questionnaire Japanese version; BMI, body mass index; CFA, confirmatory factor analysis; GFI, Goodness of FIT INDEX; CFI, Comparative FIT INDEX; RMSEA, root mean square error of approximation; AIC, Akaike Information Criterion.

\section{Data Sharing Statement}

The datasets used and/or analyzed during the current study are available from the authors on request.

\section{Ethics Approval and Informed Consent}

This study was approved by the Waseda University Institutional Committee on Human Research (application number 2018-080) and conformed to the principles outlined in the Declaration of Helsinki. All participants gave written informed consent.

\section{Acknowledgments}

We would like to thank Dr Laura E. Simons for advice of the PIPS-J translation. Also, we would like to express our 
gratitude to the participants and staff at Hasegawa Hospital for their support of the present study.

\section{Author Contributions}

All authors made a significant contribution to the work reported, whether that is in the conception, study design, execution, acquisition of data, analysis and interpretation, or in all these areas, took part in drafting, revising or critically reviewing the article, gave final approval of the version to be published, have agreed on the journal to which the article has been submitted, and agree to be accountable for all aspects of the work.

\section{Funding}

This work was supported by the MEXT-Supported Program for the Strategic Research Foundation at Private Universities, 2015-2019, of the Japan Ministry of Education, Culture, Sports, Science and Technology (S1511017).

\section{Disclosure}

The authors report no conflicts of interest in this work.

\section{References}

1. Yoshimura N, Akune T, Fujiwara S, et al. Prevalence of knee pain, lumbar pain and its coexistence in Japanese men and women: the Longitudinal Cohorts of Motor System Organ (LOCOMO) study. J Bone Miner Metab. 2014;32(5):524-532. doi:10.1007/s00774-013-0522-1

2. Hirano K, Imagama S, Hasegawa Y, Ito Z, Muramoto A, Ishiguro N. Impact of low back pain, knee pain, and timed up-and-go test on quality of life in community-living people. J Orthop Sci. 2014;19 (1):164-171. doi:10.1007/s00776-013-0476-0

3. Williams ACDC, Fisher E, Hearn L, Eccleston C. Psychological therapies for the management of chronic pain (excluding headache) in adults. Cochrane Database Syst Rev. 2020;8(8). doi:10.1002/ 14651858.CD007407.pub2

4. Hofmannn SG, Asmundson GJ. Acceptance and mindfulness-based therapy: new wave or old hat? Clin Psychol Rev. 2008;28(1):1-16. doi:10.1016/j.cpr.2007.09.003

5. Feliu-Soler A, Montesinos F, Gutiérrez-Martínez O, Scott W, McCracken LM, Luciano JV. Current status of acceptance and commitment therapy for chronic pain: a narrative review. $J$ Pain Res. 2018;10(11):2145-2159. doi:10.2147/JPR.S144631

6. Wetherell JL, Petkus AJ, Alonso-Fernandez M, Bower ES, Steiner AR, Afari N. Age moderates response to acceptance and commitment therapy vs. cognitive behavioral therapy for chronic pain. Int J Geriatr Psychiatry. 2016;31(3):302-308. doi:10.1002/gps.4330

7. McCracken LM, Vowles KE, Eccleston C. Acceptance of chronic pain: component analysis and a revised assessment method. Pain. 2004;107 (1):159-166. doi:10.1016/j.pain.2003.10.012

8. Wicksell RK, Renöfält J, Olsson GL, Bond FW, Melin L. Avoidance and cognitive fusion-central components in pain related disability? Development and preliminary validation of the Psychological Inflexibility in Pain Scale (PIPS). Eur J Pain. 2008;12(4):491-500. doi:10.1016/j.ejpain.2007.08.003
9. Wicksell RK, Lekander M, Sorjonen K, Olsson GL. The Psychological Inflexibility in Pain Scale (PIPS)-statistical properties and model fit of an instrument to assess change processes in pain related disability. Eur J Pain. 2010;14(7):771. doi:10.1016/j. ejpain.2009.11.015

10. Hayes SC, Luoma JB, Bond FW, Masuda A, Lillis J. Acceptance and commitment therapy: model, processes and outcomes. Behav Res Ther. 2006;44(1):1-25. doi:10.1016/j.brat.2005.06.006

11. Hedman-Lagerlöf M, Hedman-Lagerlöf E, Axelsson E, et al. Internet-delivered exposure therapy for fibromyalgia: a randomized controlled trial. Clin J Pain. 2018;34(6):532-542. doi:10.1097/ AJP.0000000000000566

12. Wicksell RK, Kemani M, Jensen K, et al. Acceptance and commitment therapy for fibromyalgia: a randomized controlled trial. Eur J Pain. 2013;17(4):599-611. doi:10.1002/j.1532-2149.2012.00224.x

13. Kemani MK, Hesser H, Olsson GL, Lekander M, Wicksell RK. Processes of change in acceptance and commitment therapy and applied relaxation for long-standing pain. Eur J Pain. 2016;20 (4):521-531. doi:10.1002/ejp.754

14. Hedman-Lagerlöf M, Hedman-Lagerlöf E, Ljótsson B, Wicksell RK, Flink I, Andersson E. Cost-effectiveness and cost-utility of internet-delivered exposure therapy for fibromyalgia: results from a randomized, controlled trial. $J$ Pain. 2019;20(1):47-59. doi:10.1016/j.jpain.2018.07.012

15. Rodero B, Pereira JP, Pérez-Yus MC, et al. Validation of a Spanish version of the psychological inflexibility in pain scale (PIPS) and an evaluation of its relation with acceptance of pain and mindfulness in sample of persons with fibromyalgia. Health Qual Life Outcomes. 2013;11(1):62. doi:10.1186/1477-7525-11-62

16. Trompetter HR, Bohlmeijer ET, Baalen B, et al. The Psychological Inflexibility in Pain Scale (PIPS) exploration of psychometric properties in a heterogeneous chronic pain sample. Eur J Psychol Assess. 2014;30(4):289-295. doi:10.1027/1015-5759/a000191

17. Barke A, Riecke J, Rief W, Glombiewski JA. The Psychological Inflexibility in Pain Scale (PIPS) - validation, factor structure and comparison to the Chronic Pain Acceptance Questionnaire (CPAQ) and other validated measures in German chronic back pain patients. BMC Musculoskelet Disord. 2015;16:171. doi:10.1186/s12891-0150641-z

18. Omidi A, Zanjani Z, Kashani MHF, Kakhki RD. The evaluation of the construct and convergent validity and reliability of psychological inflexibility in pain scale in individuals with migraine headache. Iran J Psychiatry Behav Sci. 2018;12(3):e63132.

19. Ghomian S, Naseri MRS, Masumian S, Nuri TMZN. Psychometric feature of the child and parent versions of psychological inflexibility in pain scale (PIPS) in children with chronic pain and their parents. Caspian J Pediatr. 2017;3(2):241-247.

20. Vasiliou VS, Michaelides MP, Kasinopoulos O, Karekla M. Psychological inflexibility in pain scale: Greek adaptation, psychometric properties, and invariance testing across three pain samples. Psychol Assess. 2019;31(7):895-904. doi:10.1037/pas0000705

21. Xie CJ, Xu XH, Ou MJ, Chen YY. Chinese version of the psychological inflexibility in pain scale for cancer patients reporting chronic pain. Cancer Nurs. 2019;10(23). doi:10.1097/NCC.000000000000 0772

22. Bond FW, Hayes SC, Baer RA, et al. Preliminary psychometric properties of the acceptance and action questionnaire-II: a revised measure of psychological flexibility and acceptance. Behav Ther. 2011;42(4):676-688. doi:10.1016/j.beth.2011.03.007

23. Shima T, Yanagihara M, Kawai T, Kumano H Validation of the Japanese version of the acceptance and action questionnaire-II. Oral presented at: 77th Annual Convention Japanese Psychological Association Proceedings; September 19; 2013; Hokkaido, Pref.

24. Gillanders DT, Bolderston H, Bond FW, et al. The development and initial validation of the cognitive fusion questionnaire. Behav Ther. 2014;45(1):83-101. doi:10.1016/j.beth.2013.09.001 
25. Shima T, Yanagihara M, Kawai T, Kumano H. Validation of the Japanese version of the cognitive fusion questionnaire. Japanese Association of Behavioral Therapies. Japan $J$ Behav Ther. 2016;73-83.

26. Wild D, Grove A, Martin M, et al. Principles of good practice for the translation and cultural adaptation process for Patient-Reported Outcomes (PRO) measures: report of the ISPOR task force for translation and cultural adaptation. Value Health. 2005;8(2):94-104. doi:10.1111/j.1524-4733.2005.04054.x
27. Schermelleh Engel K, Moosbrugger H, Müller H. Evaluating the fit of structural equation models: tests of significance and descriptive goodness of fit measures. MPR-Online. 2003;8(8):23-74.

28. Muthén LK, Muthén BO. How to use a Monte Carlo study to decide on sample size and determine power. Struct Equ Model. 2002;9 (4):599-620. doi:10.1207/S15328007SEM0904_8

\section{Publish your work in this journal}

The Journal of Pain Research is an international, peer reviewed, open access, online journal that welcomes laboratory and clinical findings in the fields of pain research and the prevention and management of pain. Original research, reviews, symposium reports, hypothesis formation and commentaries are all considered for publication. The manuscript management system is completely online and includes a very quick and fair peer-review system, which is all easy to use. Visit http:// www.dovepress.com/testimonials.php to read real quotes from published authors. 